\title{
A unifying hypothesis and a single name for a complex globally emerging infection: hantavirus disease
}

\author{
J. Clement • P. Maes • K. Lagrou • M. Van Ranst • \\ N. Lameire
}

Received: 10 October 2011 /Accepted: 11 October 2011 /Published online: 9 November 2011

(C) Springer-Verlag 2011

In the January 2011 issue of this journal, Swedish authors described three severe cases of predominantly pulmonary infection with the European hantavirus Puumala virus (PUUV), leading to death due to refractory shock in two of these patients [1]. Of note, the kidneys in these two fatal cases had, on autopsy, no prominent inflammatory infiltrates or haemorrhages, in contrast with the lungs which showed extensive interstitial oedema and mononuclear cell infiltrates, mainly $\mathrm{CD} 8^{+} \mathrm{T}$ lymphocytes. As the authors justly point out, even in the title of their communication, it is now, perhaps, time to revise the sacro-saint paradigm existing since 1994 of two "different" infectious diseases caused by the same genus of rodent-borne hantaviruses of the Old and the New World, respectively. The former would target mainly the human kidney, and the latter mainly the human lung, resulting in the so-called "haemorrhagic fever with renal syndrome" (HFRS) [2] or the "hantavirus pulmonary syndrome" (HPS) [3]. When it appeared that the failing heart was, in fact, the most direct cause of death in refractory shock in HPS, yet another name, "hantavirus cardio-pulmonary syndrome" (HCPS), was added to the already bewildering list of over 60 mostly exotic synonyms for a disease described already in 1913 by Russian

J. Clement $(\bowtie) \cdot$ P. Maes $\cdot$ K. Lagrou $\cdot$ M. Van Ranst

National Reference Laboratory for Hantavirus Infections,

University Hospital Gasthuisberg,

Herestraat 49,

3000 Leuven, Belgium

e-mail: jan.clement@uzleuven.be

\section{N. Lameire}

Nephrology, University Hospital Gent,

De Pintelaan 85,

9000 Gent, Belgium

e-mail: norbert.lameire@ugent.be doctors in Vladivostok. On the other side of the Eurasian landmass and in 1934, Swedish doctors described an epidemic renal affection which they called "nephropathia epidemica" (NE), which was proven in 1979 to be, in fact, a milder variant of HFRS, caused by PUUV [4].

To date, 23 distinct species of hantaviruses have been recognized, each carried by their more or less specific rodent or insectivore reservoir. The most important pathogens are Hantaan (HTNV) and Seoul virus (SEOV) in the Far-East (where $>90 \%$ of worldwide hantavirus infections occur), PUUV and Dobrava-Belgrade virus (DOBV) in Europe and Russia, and Sin Nombre (SNV) and Andes virus (ANDV) in the Americas [5]. The first HPS report that appeared in 1994 [3] described "a newly recognized disease" which was of paramount importance for a better understanding of an emerging viral infection in the New World, and generated an explosive surge in hantavirus research. However, H(C)PS was, and remains, a rare disease, with only 560 confirmed cases in the USA during the 1993-2010 period [6] (meaning 30 cases/year) and about 2,500 cases in the entire Americas, albeit with a much higher case fatality rate (CFR) of $35 \%$ [7]. This is in stark contrast with the current $0.1-0.2 \%$ CFR for PUUV infections with high morbidity in the Old World, with now over 50,000 registered NE cases in Europe, and even over 175,000 in Western Russia. In some peak years, Russia witnessed more than 10,000 cases/year (e.g. 11,413 in 1985), whereas registered NE numbers in Western Europe recently took epidemic proportions (e.g. 3,259 in Finland, 2008, and 1,874 in Germany, 2010), probably as a result of global warming [8]. Thus, it should not come as a surprise that Russian or European clinicians had or have now identified clinical characteristics claimed as being specific for "American HPS". The Centers for Disease 
Control and Prevention (CDC), Atlanta, GA, USA, propose a total of eight distinctive clinical criteria for its "Hantavirus Pulmonary Syndrome Case Report Form" [9]: (1) fever, (2) thrombocytopaenia, )3) elevated haematocrit (Hct), (4) elevated serum creatinine, (5) left shift leukocytosis with a high percentage of "atypical lymphocytes", (6) need for supplemental oxygen, (7) need for intubation (and mechanical ventilation), and (8) chest $\mathrm{Rx}$ showing unexplained bilateral infiltrates or being suggestive of acute respiratory distress syndrome (ARDS). It is gratifying to see that at least one pivotal renal parameter is now used for the diagnosis of a "pulmonary syndrome". Indeed, HPS was originally announced as having little or no renal involvement $[3,10]$, but increased levels of serum creatinine are now confirmed as being present in $42 \%$ of all HPS cases in the USA and even in 56\% of fatal cases [7]. Furthermore, when it is generally agreed that CDC criteria 1 to 4 are encountered in virtually all moderate to severe hantavirus infections worldwide, it can be questioned, as was done already 17 years ago [11], whether criteria 5 to 8 really are to be considered as truly unique to the American situation. Russian authors reported proven PUUV infections in five young and previously healthy patients, without any elevated creatinine levels or even proteinuria, without oliguria or polyuria, but with bilateral infiltrates on $\mathrm{Rx}$ chest in $3 / 5$ cases and pleural effusion in $1 / 5$ cases. These authors, working in one of the hotspots of PUUV endemicity in Western Russia, suggested already in 1993 that different clinical entities may exist, one of these being (we quote) "a quite severe febrile condition without renal involvement" [12].

While it seems acceptable that Old, respectively New World pathogens might have a somewhat different "organ tropism", and, hence, a somewhat different clinical picture, it is unlikely that these genetically related viruses should be radically different pathogens, as originally stated $[10,13]$. Moreover, hantavirus pathogenicity is not determined by the negligible viral tissue damage, but, rather, by the immunological response of the human host, the so-called "cytokine storm" [5, 13]. In a series of clinical observations and in vitro experiments, Hayasaka et al. and Terajima and Ennis suggested that increased capillary permeability observed in both H(C)PS and HFRS may be caused by a common immunopathological mechanism, i.e. hantavirus-specific cytotoxic $\mathrm{CD}^{+} \mathrm{T}$ lymphocytes, attacking endothelial cells presenting viral antigens on their surface [14, 15].

In hindsight, it may now seem a bit premature that some authors, without having seen the patients but confronted in 1994 with the first reports of "European HPS", should dismiss these forms merely as a complication of oligo/ anuria, leading to lung oedema secondary to fluid overload, and, hence, a form of right-handed cardiac failure [10].
First, NE cases sometimes presented with clear lung symptoms well before oligo/anuria and fluid overload were properly initiated. One of the earliest recorded (1986) Belgian NE cases involved a 53-year-old female presenting with $39^{\circ} \mathrm{C}$ fever, cough, dyspnoea, bibasilar lung infiltrates, hypoxaemia (partial pressure of arterial oxygen $\left[\mathrm{PaO}_{2}\right]$ of $62 \mathrm{~mm} \mathrm{Hg}$ ), hypocapnia and a severely restricted lung diffusion capacity (carbon monoxide diffusion capacity, $48 \%$ of the predicted value), necessitating $\mathrm{O}_{2}$ supplementation. This form of symptomatic viral ARDS without oliguria could not be clinically explained by fluid overload, nor by the very mild degree of subsequent renal involvement (serum creatinine level at admission 0.9 , peak value only $1.6 \mathrm{mg} / \mathrm{dL}$ ), and showed a spontaneous remission [16]. Second, during the first (1993) NE epidemic in Belgium, a total of seven cases suffered from hypoxia (spread $\mathrm{PaO}_{2} 39$ to $74 \mathrm{~mm} \mathrm{Hg}$ ) and hypocapnia $\left(\mathrm{PaCO}_{2} 24\right.$ to $\left.36 \mathrm{mmHg}\right)$. In all of these cases, fluid overload was excluded on the basis of normal values of continuously monitored central venous pressure (CVP) [11]. In the most severe case $\left(\mathrm{PaO}_{2} 39\right.$ and $\mathrm{PaCO}_{2} 28 \mathrm{~mm} \mathrm{Hg}$ ), needing both dialysis and life-saving mechanical ventilation, signs of cardiac decompensation were excluded by Swan-Ganz catheter monitoring (pulmonary capillary wedge pressure $5 \mathrm{~mm} \mathrm{Hg}$, pulmonary artery pressure $14 / 8 \mathrm{~mm} \mathrm{Hg}$ ) [11]. Third, this same patient had a low cardiac index $\left(2.61 / \mathrm{min} / \mathrm{m}^{2}\right)$, a systemic vascular resistance of $1.229 \mathrm{dyn} \mathrm{s} \mathrm{cm}{ }^{-5}$ and extreme thrombocytopaenia $\left(11,000 / \mathrm{mm}^{3}\right)$, followed by disseminated intravascular coagulation (DIC), all of which are signs considered as typical for HPS according to CDC guidelines $[9,13]$.

Other early European reports documenting more severe pulmonary rather than renal involvement, and implicating hantaviruses distinct from PUUV, are available as well. The first isolation in Europe of a murine HTNV-like hantavirus (in hindsight, probably DOBV) and dated 1986, was from the urine of a 21-year-old Greek soldier, infected during manoeuvres in Porogia (northern Greece) and suffering from acute pulmonary oedema, and later from acute renal failure (ARF), prompting both life-saving ventilation and acute dialysis [17]. On admission, this case fulfilled all eight current CDC criteria for HPS, with fever of $39^{\circ} \mathrm{C}$, severe thrombocytopaenia and even DIC, Hct of $59 \%$, WBC of $18,770 / \mathrm{mm}^{3}$ with $10 \%$ "large lymphocytes" and pulmonary oedema initially even resistant to massive fluid extraction during dialysis. This patient had an admission CVP of only $5 \mathrm{~cm}$ of $\mathrm{H}_{2} \mathrm{O}$, making the hypothesis of secondary overwhelming fluid overload highly improbable. A 19-year-old British soldier stationed in Bosnia as a member of the United Nations Protection Force (UNPROFOR) was reported as a sudden severe case of wild rat-transmitted SEOV 
(though, in hindsight, probably DOBV)-induced ARDS followed by ARF, urgently needing intubation and ventilation in a local military field hospital, emergency repatriation by air while on positive-pressure $\mathrm{O}_{2}$ supplementation, followed by intensive care therapy in London, UK [18]. Another DOBV case in northern Germany developed life-threatening pulmonary oedema 2 days before any renal impairment [19]. A first HFRS case associated with Tula virus infection, presenting both renal and pulmonary involvement, was documented in northern Germany [20].

Thus, and as predicted [21], there is increasing evidence of a considerable overlap of symptoms in both syndromes. Moreover, symptoms are rarely complete: in PUUV infections, since only a tiny minority (probably less than $10 \%$ ) develops symptoms severe enough for a hospitalisation [21], whereas for a local H(C)PS agent like Choclo virus in Panama, pauci- or asymptomatic seroconverters outnumbered full-blown H(C)PS cases by 14 to 1 in a recent study [22]. Should we continue to call symptomatic New World hantavirus infections without any pulmonary involvement $[22,23]$ "H(C)PS", or the many Old World infections without much renal involvement still "HFRS"? And how to name the fatal cases with both severe ARF and hypoxia, prompting ventilation and dialysis, as recently found in India, and probably caused by a "new" hantavirus [24]? These denominations become utterly paradoxical if we learn, for instance, that $10 \%$ of South-American ANDV-induced "pulmonary syndromes", in fact, need dialysis for acute treatment [13], whereas only $5 \%$ or even less of European "nephropathia" cases needs the same [8]. Moreover, Russian scientists, reluctant to use the European denomination NE for PUUV infections in their own country, prefer to stick to the official World Health Organization (WHO) name HFRS, thus, adding to the semantic confusion of non-initiated readers. Worse, the definition of what exactly a "renal syndrome" should be has never been given, not even when the name was officially coined by the WHO in 1983 [2]. If a "renal syndrome" is clear proteinuria, then virtually all Old World hantavirus infections fully comply [25], but so do most New World infections. It should be remembered that, even amongst the 17 HPS patients originally described in 1994 , already $40 \%$ had $\geq 2+$ proteinuria on admission [3], a figure later increasing to $100 \%$, at least for all $\mathrm{H}(\mathrm{C}) \mathrm{PS}$ cases other than those caused by SNV [13]. For a full assessment of this distinctive feature, it can only be regretted that the CDC did not simply include proteinuria amongst its criteria for "H(C)PS" as the easiest, quickest and cheapest test available. Moreover, proteinuria is minimal or absent in other febrile affections that might initially mimic $\mathrm{H}(\mathrm{C}) \mathrm{PS}$, such as plague, tularaemia and rickettsioses.
As for "renal impairment" or ARF, the definitions become increasingly unclear: when starts the "failure" of renal function? Up to 2003, several definitions had been used to define ARF [26]. Acute kidney injury (AKI) has recently become the preferred term to describe acute renal impairment, with "failure" or "ARF" restricted to patients needing renal replacement therapy (RRT). In 2004, a workgroup of experts proposed a multi-level and evidence-based classification system for AKI, identified by the acronym RIFLE (Risk, Injury, Failure, Loss of kidney function, and End-stage kidney disease). AKI was first defined on the basis of either a 1.5 -fold increase in serum creatinine levels, a decrease in estimated glomerular filtration rate by $>25 \%$ or a decline in the urine output to $<0.5 \mathrm{ml} / \mathrm{kg} / \mathrm{h}$ over $6 \mathrm{~h}[27,28]$. The Acute Kidney Injury Network (AKIN) group further modified this definition by adding an increase in the creatinine level by $\geq 0.3 \mathrm{mg} / \mathrm{dl}$ as criterion [29]. While these new criteria might not always be fully applicable in hantavirus infections in view of the rapid and spontaneous self-remittance without sequelae of renal symptoms, they have at least the benefit of clarity and current general agreement, even when the decision of when best to start RRT should remain a purely clinical one [30]. Nowadays, virtually each major hantavirus research team handles its own criteria for distinguishing "mild", "moderate" and "severe" renal involvement.

For this emerging zoonosis, the only one (together with leptospirosis) with a global distribution, and probably the most underestimated cause worldwide of infectious AKI, a more streamlined approach is really needed for classification, and even for research $[8,25]$. For instance, no conclusive mechanism has been forwarded so far to explain the sudden initial proteinuria. American authors found, however, that, due to extreme capillary leaking, pulmonary effusions in H(C)PS can have almost the same protein composition as plasma [13]. Bearing in mind that hantavirus-induced proteinuria, in spite of a puzzling absence of glomerular lesions that can be detected by light microscopy, immunofluorescence or electron microscopy, often reaches nephrotic levels and is always unselective [31], the most straightforward explanation is, again, the temporary leakage of a proteinrich filtrate through hyper-permeable endothelium in the glomerular capillary loops, together with varying degrees of initial tubulopathy. If confirmed by comparative studies, this hypothesis could further underline similarities between H(C)PS and HFRS instead of differences, thus, corroborating a common, rather than a divergent pathogenesis. In such a case, maintaining disease names based on varying or overlapping symptoms makes little sense, and a unifying name becomes even more mandatory. With the advent of biomolecular techniques such as reverse transcription polymerase chain reaction 
(RT-PCR), pinpointing the exact nature of infecting hantavirus species and discovering even new pathogens without a proper virus isolation [3,21], it is, perhaps, time now to refine also the old denominations of this global disease. A good start would be a simple, short name like "hantavirus disease", having the additional merit of fulfilling at least part of Koch's postulate, which names of various symptoms never can do. This way, the 1984 proposition of Desmyter et al. [32], after having unravelled the first documented European (laboratory) hantavirus outbreak outside of Scandinavia [33], could finally be accepted.

\section{References}

1. Rasmuson J, Andersson C, Norrman E, Haney M, Evander M, Ahlm C (2011) Time to revise the paradigm of hantavirus syndromes? Hantavirus pulmonary syndrome caused by European hantavirus. Eur J Clin Microbiol Infect Dis 30:685-690

2. World Health Organization (WHO) (1983) Haemorrhagic fever with renal syndrome: memorandum from a WHO meeting. Bull World Health Organ 61:269-275

3. Duchin JS, Koster FT, Peters CJ, Simpson GL, Tempest B, Zaki SR, Ksiazek TG, Rollin PE, Nichol S, Umland ET, Moolenaar RL, Reef SE, Nolte KB, Gallaher MM, Butler JC, Breiman RF; The Hantavirus Study Group (1994) Hantavirus pulmonary syndrome: a clinical description of 17 patients with a newly recognized disease. N Engl J Med 330:949-955

4. Lee HW, Lee PW, Lähdevirta J, Brummer-Korventkontio M (1979) Aetiological relation between Korean haemorrhagic fever and nephropathia epidemica. Lancet 1(8109):186-187

5. Maes P, Clement J, Gavrilovskaya I, Van Ranst M (2004) Hantaviruses: immunology, treatment, and prevention. Viral Immunol 17:481-497

6. Centers for Disease Control and Prevention (CDC) (2011) Notes from the field: hantavirus pulmonary syndrome-Maine, April 2011. MMWR Morb Mortal Wkly Rep 60(23):786

7. Macneil A, Ksiazek TG, Rollin PE (2011) Hantavirus pulmonary syndrome, United States, 1993-2009. Emerg Infect Dis 17 (7):1195-1201

8. Clement J, Maes P, Barrios JM, Verstraeten WW, Amirpour Haredasht S, Ducoffre G, Aerts J-M, Van Ranst M (2011) Global warming and epidemic trends of an emerging viral disease in Western-Europe: the Nephropathia epidemica case. In: Casalegno S (ed) Global warming impacts - case studies on the economy, human health, and on urban and natural environments. InTech Open Access Publisher, Rijeka, Croatia, pp 39-52. Available online at: http://www.intechopen.com/ articles/show/title/global-warming-and-epidemic-trends-of-anemerging-viral-disease-in-western-europe-the-nephropathia-e

9. Centers for Disease Control and Prevention (CDC) (2010) Hantavirus pulmonary syndrome (hantavirus disease) (HPS), 2010 case definition. CDC, Atlanta, GA. Available online at: http://www. cdc.gov/osels/ph_surveillance/nndss/casedef/hantaviruscurrent.htm. Accessed 1 September 2011

10. Duchin JS, Breiman RF, Butler JC, Peters CJ, Koster FT (1994) Hantavirus pulmonary syndrome in New England and Europe, author reply. N Engl J Med 331:547

11. Clement J, Colson P, McKenna P (1994) Hantavirus pulmonary syndrome in New England and Europe. N Engl J Med 331:545-546
12. Alexeyev OA, Baranov BA (1993) Puumala virus infection without signs of renal involvement. Scand J Infect Dis 25 (4):525-527

13. Peters CJ, Khan AS (2002) Hantavirus pulmonary syndrome: the new American hemorrhagic fever. Clin Infect Dis 34 (9):1224-1231

14. Hayasaka D, Maeda K, Ennis FA, Terajima M (2007) Increased permeability of human endothelial cell line EA.hy926 induced by hantavirus-specific cytotoxic $\mathrm{T}$ lymphocytes. Virus Res 123:120-127

15. Terajima M, Ennis FA (2011) T cells and pathogenesis of hantavirus cardiopulmonary syndrome and hemorrhagic fever with renal syndrome. Viruses 3:1059-1073. doi:10.3390/ v3071059

16. Buysschaert M, Pirson F, Mendez Mayorga V, Van der Groen G, Coche E (1987) Hantavirus nephropathy in Belgium: description of 2 new cases originating in southern provinces. Acta Clin Belg 42:311-315 (in French)

17. Antoniades A, Grekas D, Rossi CA, LeDuc JW (1987) Isolation of a hantavirus from a severely ill patient with hemorrhagic fever with renal syndrome in Greece. J Infect Dis 156(6):1010-1013

18. Stuart LM, Rice PS, Lloyd G, Beale RJ (1996) A soldier in respiratory distress. Lancet 347:30

19. Schütt M, Meisel H, Krüger DH, Ulrich R, Dalhoff K, Dodt C (2004) Life-threatening Dobrava hantavirus infection with unusually extended pulmonary involvement. Clin Nephrol 62 (1):54-57

20. Klempa B, Meisel H, Räth S, Bartel J, Ulrich R, Krüger DH (2003) Occurrence of renal and pulmonary syndrome in a region of northeast Germany where Tula hantavirus circulates. J Clin Microbiol 41:4894-4897

21. Clement J, Heyman P, McKenna P, Colson P, Avsic-Zupanc T (1997) The hantaviruses of Europe: from the bedside to the bench. Emerg Infect Dis 3:205-211

22. Armien B, Pascale JM, Munoz C, Lee SJ, Choi KL, Avila M, Broce C, Armien AG, Gracia F, Hjelle B, Koster F (2011) Incidence rate for hantavirus infections without pulmonary syndrome, Panama. Emerg Infect Dis 17(10):1936-1939

23. Kitsutani PT, Denton RW, Fritz CL, Murray RA, Todd RL, Pape WJ, Wyatt Frampton J, Young JC, Khan AS, Peters CJ, Ksiazek TG (1999) Acute Sin Nombre hantavirus infection without pulmonary syndrome, United States. Emerg Infect Dis 5(5):701-705

24. Clement J, Maes P, Muthusethupathi M, Nainan G, Van Ranst M (2006) First evidence of fatal hantavirus nephropathy in India, mimicking leptospirosis. Nephrol Dial Transplant 21:826-827

25. Clement J, Maes P, Van Ranst M (2007) Acute kidney injury in emerging, non-tropical infections. Acta Clin Belg 62:387395

26. Mehta RL, Chertow GM (2003) Acute renal failure definitions and classification: time for change? J Am Soc Nephrol 14:21782187

27. Kellum JA, Levin N, Bouman C, Lameire N (2002) Developing a consensus classification system for acute renal failure. Curr Opin Crit Care 8:509-514

28. Bellomo R, Ronco C, Kellum JA, Mehta RL, Palevsky P; Acute Dialysis Quality Initiative workgroup (2004) Acute renal failuredefinition, outcome measures, animal models, fluid therapy and information technology needs: the Second International Consensus Conference of the Acute Dialysis Quality Initiative (ADQI) Group. Crit Care 8:R204-R212

29. Mehta RL, Kellum JA, Shah SV, Molitoris BA, Ronco C, Warnock DG, Levin A; Acute Kidney Injury Network (2007) 
Acute Kidney Injury Network: report of an initiative to improve outcomes in acute kidney injury. Crit Care 11:R31

30. Lameire N, Vanbiesen W, Vanholder R (2011) When to start dialysis in patients with acute kidney injury? When semantics and logic become entangled with expectations and beliefs. Crit Care 15(4): 171

31. Clement J, Mustonen J, Van Damme B, Helin H, Maes P, Van Ranst M (2011) Severe crescentic glomerulonephritis linked to an acute Hantaan virus infection? Nephrol Dial Transpl 26:14481449. doi:10.1093/ndt/gfr134

32. Desmyter J, van Ypersele de Strihou C, van der Groen G (1984) Hantavirus disease. Lancet 2:158

33. Desmyter J, LeDuc JW, Johnson KM, Brasseur F, Deckers C, van Ypersele de Strihou C (1983) Laboratory rat associated outbreak of haemorrhagic fever with renal syndrome due to Hantaan-like virus in Belgium. Lancet 2(8365-66):1445-1448 